\title{
FILMES E NEGRITUDE EM SALA DE AULA: ESSA RELAÇÃo É POSSÍVEL?
}

\section{MOVIES AND BLACK RACE IN THE CLASSROOM: THIS RELATIONSHIP IS POSSIBLE?}

\section{Teresa Kazuko Teruya ${ }^{1}$ Delton Aparecido Felipe ${ }^{2}$}

RESUMO: Este artigo apresenta um relato de experiência com professores(as) que participaram de um curso de extensão realizado no decorrer de 2008, intitulado: "O cinema no ensino de história e cultura afro-brasileira e africana na educação básica”. As Diretrizes e Bases da Educação Nacional estabelecem o cumprimento da Lei 10.639/2003 para educação étnico-racial. Para problematizar e contribuir com a educação da negritude no Brasil, este texto discute as potencialidades das narrativas fílmicas na sala de aula para o ensino da história e da cultura afro-brasileira e africana. Os resultados indicam a existência do potencial pedagógico da filmografia, mesmo que os(as) docentes não saibam explorar as narrativas fílmicas que ajudem seus (suas) alunos(as) a visualizar o "outro". Conclui-se que a utilização de filmes como fonte de estudo ou como ferramenta pedagógica exige uma ação pedagógica crítica de decodificação, interpretação e desconstrução das narrativas fílmicas, para perceber o registro das ações humanas representadas na tela.

PALAVRAS-CHAVE: Formação de professores. Tecnologia educacional. Cultura afro-brasileira. Educação dos negros.

ABSTRACT: This paper presents an experience with teachers who participated in an extension course conducted during 2008 entitled: "The movies in teaching history and culture african-Brazilian and African basic education." Guidelines and National Education establish compliance with the Law $10.639 / 2003$ education for ethnic-racial. To discuss and contribute to the education of blackness in Brazil, this paper discusses the potential of film narratives in the classroom for the teaching of history and Afro-Brazilian and African culture. The results indicate the existence of potential pedagogical filmography, even teachers do not know how to exploit their film narratives that help students visualize the "other." We conclude that the use of films as a source of study or as a pedagogical tool requires a critical pedagogical action decoding, interpretation and deconstruction of film narratives to understand the record of human actions depicted on the screen.

KEYWORDS: Teacher training. Educational technology. African-Brazilian culture. Education of blacks.

\footnotetext{
${ }^{1}$ Docente do Departamento de Teoria e Prática da Educação e do Programa de Pós-Graduação em Educação da Universidade Estadual de Maringá - Maringá, PR - Brasil. E-mail: tkteruya@uem.br

${ }^{2}$ Doutorando em Educação - Universidade Estadual de Maringá - Maringá, PR - Brasil. E-mail: ddelton@gmail.com
}

Recebido em: 17/08/2011 - Aceito em: 07/02/2013.

\begin{tabular}{l|l|l|l|l|l|l}
\hline (C) ETD -Educ. temat. digit. & Campinas, SP & v.15 & n.1 & p. 145-160 & jan./abr. 2013 & ISSN 1676-2592 \\
\hline
\end{tabular}




\section{INTRODUÇÃO}

A utilização dos filmes na formação de professores (as) para o ensino de história e cultura afro-brasileira e africana nas salas de aula brasileira é uma possibilidade de problematizar a educação da negritude no Brasil. Pensando nisso, realizamos uma intervenção pedagógica com os(as) professores(as) da rede pública estadual da cidade de Maringá, no estado do Paraná.

O Relatório das Diretrizes Curriculares Nacionais para Educação das Relações Étnico-Raciais e para o Ensino de História e Cultura Afro-Brasileira e Africana, publicado em 2004, afirma que uma das principais estratégias para combater o racismo, o preconceito e a marginalização vivenciados pela população preta e parda/negra no Brasil é viabilizar condições reais para as mudanças necessárias. Dessa forma, a educação étnico-racial, proposta na Lei 10.639/2003, que estabelece a inclusão obrigatória da temática "história e cultura afro-brasileira" no currículo oficial da rede de ensino, exige dos (as) professores(as) mobilizar suas subjetividades; desconstruir noções e concepções apreendidas durante anos de formação; e enfrentar preconceitos e racismos muito além dos muros escolares. Para Santos (2006), nas escolas atuais, em que a luta pela valorização das diferenças é constante, nota-se a necessidade de desenvolver uma pedagogia que promova o questionamento permanente dos conhecimentos e dos conceitos essencialistas, ou seja, uma pedagogia que permita repensar as identidades culturais estabelecidas em nossa sociedade.

Ainda segundo Santos (1996), a sala de aula teria que se transformar em um campo de possibilidades para trocar conhecimentos, onde se possa conhecer a história do "eu" e do "outro". Ao adotar esse princípio norteador de nossa pesquisa, organizamos um curso de extensão ${ }^{3}$, em parceria com o Núcleo Regional de Educação de Maringá (NRE), intitulado "O cinema no ensino de história e cultura afro-brasileira e africana na educação básica". Destinado aos docentes do Ensino Fundamental e Médio da rede pública estadual do Paraná, o curso foi estruturado em seis encontros, que ocorreram na Universidade Estadual de Maringá, nos dias 8/04, 15/04, 22/04, 6/05,

3 Uma parte dos dados coletados nesse curso, sob a coordenação de Teresa Kazuko Teruya, foi objeto de análise da dissertação, defendida por Delton Aparecido Felipe, intitulada: Narrativas para alteridade: o cinema na formação de professores e professoras para o ensino de história e cultural afro-brasileira e africana na educação básica (FELIPE, 2009)

\begin{tabular}{l|l|l|l|l|l|l} 
(C) ETD -Educ. temat. digit. & Campinas, SP & v.15 & n.1 & p. 145-160 & jan./abr. 2013 & ISSN 1676-2592 \\
\hline
\end{tabular}


13/05 e 20/05, terças-feiras, das $8 \mathrm{~h}$ às $12 \mathrm{~h}$, totalizando 30 horas/aula no decorrer do ano de 2008. Dentre as atividades propostas, realizamos a análise de três filmes que abriram um espaço para pensar e repensar as relações étnico-raciais no Brasil e para formar docentes conscientes da necessidade de trabalhar as questões da negritude no espaço escolar.

Nesse sentido, utilizamos as narrativas fílmicas para fomentar as discussões sobre as relações étnico-raciais, com a intenção de romper com o silêncio que ainda existe em nossos currículos escolares sobre a população negra brasileira e propor ações pedagógicas que contribuam com a efetivação da Lei 10.639/2003. Assim, perguntamos ao grupo de professores(as) do Ensino Básico, participantes do curso: Quais são as potencialidades de utilizar as narrativas fílmicas em sala de aula para o ensino da história e cultura afro-brasileira e africana?

\section{USO DE FILMES NA SALA DE AULA}

Para coleta dos dados referentes ao uso de filmes em sala, aplicamos sete questionários, distribuídos ao longo do curso de extensão. No primeiro, aplicado em 08/04/2008, coletamos os posicionamentos dos(as) professores(as) participantes da pesquisa sobre o uso de filmes na sala de aula e seu conhecimento sobre a disposição da Lei 10.639/2003. Esse posicionamento foi o ponto de partida para análise.

Nessa etapa, obtivemos as representações dos docentes sobre o uso dos filmes em sala de aula, já que as imagens fílmicas foram a nossa fonte de pesquisa para pensar outras possibilidades de interpretação histórica e de produção do conhecimento que valorize o passado e o presente do povo negro. Adotamos o conceito de representação que "[...] inclui as práticas de significação e os sistemas simbólicos por meio dos quais os significados são produzidos, posicionando-nos como sujeitos. É por meio dos significados produzidos pelas representações que damos sentido a nossa experiência e àquilo que somos" (WOODWARD, 2000, p.17).

Apresentamos aqui as respostas dos questionários que, para conhecer as práticas pedagógicas com o uso de filmes em salas de aula, foram aplicados a 22 professores (as), sujeitos desta pesquisa. Esta foi a pergunta inicial: Já utilizou filmes em sala de aula? 


\section{( ) Sim ( ) Não ( ) Não, mas pretende um dia ( ) Não e nem pretende}

QUADRO 1: Apresenta o resultado das respostas a essa questão

\begin{tabular}{|c|c|c|c|c|c|}
\hline $\begin{array}{c}\text { Possíveis } \\
\text { Respostas }\end{array}$ & Sim & Não & $\begin{array}{c}\text { Não, mas } \\
\text { pretende }\end{array}$ & $\begin{array}{c}\text { Não, nem } \\
\text { pretende }\end{array}$ & $\begin{array}{c}\text { Não } \\
\text { Respondeu }\end{array}$ \\
\hline $\begin{array}{c}\text { Número de } \\
\text { Sujeitos }\end{array}$ & 20 & 0 & 1 & 00 & $1^{2}$ \\
\hline Porcentagem & $92 \%$ & $00 \%$ & $4, \%$ & $00 \%$ & $4 \%$ \\
\hline
\end{tabular}

Fonte: Questionários aplicados pelo(a) pesquisador(a) no decorrer do curso de extensão.

O quadro 1 indica que vinte professores(as) utilizam filmes em sua ação pedagógica e apenas um professor não utiliza, mas pretende. E um não respondeu a pergunta. As respostas confirmam os estudos realizados por Duarte (2002), Louro (2000) e Nova (1999) que revelam que o uso de filmes em sala de aula não é nenhuma novidade, pois o cinema e a escola vêm se relacionando há décadas. No entanto, ao verificar que tipo de relação os docentes estabelecem com a filmografia, os autores questionam quais são as metodologias que utilizam, ao projetar um filme tendo como intuito a ação pedagógica.

Para verificar como os sujeitos desta pesquisa utilizavam filmes na sala antes de participarem do curso, fizemos a seguinte pergunta: Qual o procedimento que você adota para trabalhar com filmes? Descrever.

As respostas dos(as) professores(as) foram distribuídas em três categorias, para entender a relação desses sujeitos da pesquisa com os filmes, ao utilizá-los em sala de aula. Lembramos que essas categorias são provisórias, por retratarem as respostas dos(as) professores(as) em um determinado momento e situação, o que necessariamente não expressa a totalidade de sua ação pedagógica.

\footnotetext{
${ }^{4}$ As perguntas que estão no decorrer do texto foram feitas para professores e professoras participantes do curso de extensão "O cinema na formação de professores no ensino de história e cultura afro-brasileira e africana”. Todos assinaram o Termo de Consentimento autorizando a utilização dos dados coletados para esta pesquisa, que foi submetida ao Comitê Permanente de Ética em Pesquisa Envolvendo Seres Humanos (COPEP), da Universidade Estadual de Maringá/PR, e por ele aprovada. Os termos de consentimento e os questionários aplicados estão arquivados no Programa de Pós-Graduação em Educação da Universidade Estadual de Maringá/PR.
} 


\subsection{Categoria A: Filme como ilustração (18\%)}

Esta categoria refere-se aos docentes que ainda não exploram o potencial educativo dos filmes, utilizando-os como mera ilustração de conteúdos. Esses(as) professores(as), geralmente, trabalham com filmes históricos. Os fatos ali retratados são abordados como reais e verídicos: "Filmes que retratem a época, filmes de curta duração, conversar antes com os alunos a respeito do filmes" (P.10 (f) ${ }^{5}$, grifo nosso $)^{6}$. O relato da professora sugere a preferência por filmes históricos ${ }^{7}$, com o intuito de ilustrar determinados fatos, sem questionar a visão dos produtores do filme sobre o fato retratado.

\subsection{Categoria B: Filme como complemento (64\%)}

Os sujeitos que compõem essa categoria não reduziram o papel do filme a uma simples ilustração do livro didático ou de outro recurso educativo. Entretanto, não reconheceram as narrativas fílmicas como um artefato cultural que permite a problematização de questões sociais em sala para além dos conteúdos escolares já programados: "Trabalhar primeiro conteúdo, passar o filme, fazer a relação do conteúdo com filme. Trabalho com relatórios, questões e comentários" (P.4 (f), grifo nosso). A resposta do sujeito demonstra que o filme não foi desconsiderado de todo; no entanto, na relação conteúdo-filme, este ainda continua sendo considerado apenas um apêndice do livro didático e de outros recursos didáticos.

Os filmes, nessa categoria, são trabalhados como verdades que confirmam os conteúdos dos livros didáticos, sem refletir sobre suas características de recurso formador de posicionamentos sociais. Desse modo, os docentes não observam a capacidade que as imagens fílmicas têm de fazer os(as) alunos(as) vivenciarem novas

\footnotetext{
${ }^{5}$ As referências aos sujeitos da pesquisa no corpo do trabalho estão indicadas com siglas de identificação seguidas do sexo feminino (f) e masculino (m). Exemplo: P10(f).

${ }^{6}$ A grafia dos textos dos(as) professores(as) participantes do curso foi mantida na forma original, sem mudanças ortográficas ou gramaticais.

7 "Produções cinematográficas que centram sua narrativa em períodos da História. Esses filmes são chamados de históricos ou épicos, por estabelecerem diálogos com a historiografia de diversas épocas. Alguns títulos se baseiam na reconstrução histórica de um fato, outros seguem a linha biográfica de personagens de época e há ainda os que fazem uso da ficção histórica ou criam uma adaptação literária própria com base nos fatos ocorridos" (ROSENSTONE, 2010, p.16).

\begin{tabular}{l|l|l|l|l|l|l|} 
(C) ETD - Educ. temat. digit. & Campinas, SP & v.15 & n.1 & p. 145-160 & jan./abr. 2013 & ISSN 1676-2592 \\
\hline
\end{tabular}
}


realidades e novas narrativas, contestando as narrativas hegemônicas, apresentadas como verdades universais. Além disso, essa postura reafirma a representação de que os filmes contam as verdades históricas, sem levar em consideração que a história é narrativa que perpassa por relações de poder, relações culturais e relações de trabalho.

\subsection{Categoria C: Filme como fonte de pesquisa (18\%)}

Nesta categoria, o filme é apresentado como um registro humano que deve ser interpretado e decodificado, porque carrega em si as representações da realidade. Isso significa entender que a sua leitura não se dá de forma imediata, é necessário fazer perguntas à obra fílmica e perceber que a sua constituição está permeada por valores e crenças de um tempo histórico. O filme é uma representação social que opera com símbolos, ideias, valores e crenças, despertando em seus espectadores os mais variados sentimentos (NOMA, 2000).

Geralmente levo o filme a fim de despertar alguma coisa em meus alunos (comportamento, preconceito...) e nem sempre tem haver com a disciplina (geografia) e sim com as necessidades latentes em nossos alunos que são inúmeras e pode sonhar que existe uma luz no fim do túnel ou que eu consiga tocar ou acrescentar algo em suas vidas (P.15 (f), grifo nosso).

O relato da professora apresenta o filme como recurso pedagógico que vai além da simples ilustração dos períodos históricos e/ou de complemento do livro didático. A professora reconhece o filme como recurso capaz de despertar sentimentos e de propiciar novas ações e novos posicionamentos sociais e políticos.

\section{HISTÓRIA E CULTURA AFRO-BRASILEIRA E AFRICANA EM SALA DE AULA}

Outro ponto de nossa pesquisa foi investigar as informações que os (as) professores(as) tinham sobre a Lei 10.639/2003, por isso perguntamos: Você conhece a Lei Federal 10.639/2003 CNE, que determina a obrigatoriedade do ensino de história e cultura afro-brasileira na Educação Básica? () Sim () Não

Todos os(as) professores(as) afirmaram que já conheciam as disposições da Lei

\begin{tabular}{l|l|l|l|l|l|l|} 
(C) ETD - Educ. temat. digit. & Campinas, SP & v.15 & n.1 & p. 145-160 & jan./abr. 2013 & ISSN 1676-2592 \\
\hline
\end{tabular}


Federal 10.639/ 2003. Esse fato, a nosso ver, deve-se às polêmicas geradas com a promulgação da Lei 10.639/2003 e ao intenso trabalho que alguns setores da população brasileira têm feito para efetivação dessa Lei nas escolas brasileiras. Apesar de todas as polêmicas e dos debates acalorados sobre ensino da história e da cultura afro-brasileira e africana na Educação Básica, verificamos, com os (as) professores (as) desta pesquisa, que o conhecimento da existência dessa Lei não assegura a sua efetivação. Perguntamos: Caso conheça as disposições da Lei Federal 10.639/2003 CNE, você já trabalhou seus conteúdos na sala de aula?

Obtivemos os seguintes dados: dos 22 professores (as), sujeitos da pesquisa, 11 responderam que trabalham com as temáticas referentes à negritude em sala de aula, enquanto 10 responderam que não trabalham com tais temáticas e 1 não respondeu.

Esses dados despertam algumas preocupações: a primeira se refere aos docentes que disseram não trabalhar com aspectos da Lei em sua sala. As justificativas para a não efetivação da Lei são muitas, tais como: a falta de formação dos (as) professores (as) para lidar com as questões étnico-raciais em sala de aula, a dificuldade de compreender a necessidade de efetivar a Lei, o medo de questionar os diversos padrões e tradições estabelecidos socialmente e a falta de materiais didáticos.

Para que realmente ocorra o efeito esperado pelo Movimento Negro e pelos idealizadores da Lei, que é a valorização de aspectos da cultura africana e do negro no Brasil, os conteúdos sobre a história e a cultura afro-brasileira e africana devem ser trabalhados em todos os níveis do sistema nacional de educação escolar, independentemente de os (as) professores(as) e os (as) alunos(as) serem negros(as) ou brancos (as). Estudar disposições da Lei em sala de aula é conhecer partes da história da negritude brasileira que foram ignoradas pelas metanarrativas de cunho eurocêntrico.

A segunda preocupação gerada pelos dados da pergunta acima refere-se ao dimensionamento teórico atribuído pelos(as) professores(as) aos conteúdos escolares com o intuito de efetivar a Lei. Como afirma Silva (1998), os conteúdos programados nos currículos escolares, muitas vezes, contribuem para a marginalização do "outro", por mostrar só uma versão da história. Pensando nisso, a efetivação da Lei 10.639/2003 deve passar por um redimensionamento e questionamento dos conteúdos escolares, a fim de que os múltiplos sujeitos sociais sejam vistos sem preconceito e discriminação na escola. 
Outra pergunta feita aos docentes foi esta: Os materiais didáticos disponíveis pelo governo nas escolas públicas permitem trabalhar com os dispositivos da Lei 10.639/2003? ( ) sim ( ) não. As respostas para esta questão também nos levaram a refletir sobre os obstáculos para a efetivação da Lei.

Embora 7 docentes tivessem respondido que os materiais fornecidos permitem trabalhar com os dispositivos da Lei em sala de aula, a maioria dos(as) professores(as), 15 dos 22 sujeitos da pesquisa, respondeu que os materiais disponibilizados pelo governo não são suficientes para abarcar os dispositivos da Lei 10.639/2003 em sala de aula. Disseram também que, no currículo escolar e nos livros didáticos, ainda estão presentes textos e ilustrações estereotipadas dos povos africanos, apresentando-os como pré-históricos, selvagens e não civilizados. Os docentes do curso afirmam que, em algumas publicações editoradas para serem utilizadas em sala de aula, não há preocupação com o contexto cultural dos povos africanos, nem com o negro no Brasil, o que pode dar margem a interpretações dúbias e estereotipadas a respeito dos africanos e dos afro-brasileiros.

Oliveira e Lins (2008) afirmam que as polêmicas e os debates em torno da Lei sobre a composição da população brasileira incentivaram a produção de variados materiais didáticos, utilizando diferentes suportes e linguagens que abordam os diferentes grupos formadores da população nacional. Por exemplo, investimentos nas produções de narrativas para problematizar a vivência da população negra na sociedade e na escola. Podemos citar o filme de curta metragem: Vista a minha pele ${ }^{8}$, feito em consonância com o espírito da Lei.

Os livros didáticos, apesar de ainda serem insuficientes, já trazem a história da África e dos afro-brasileiros em uma perspectiva que os valorize. As produções no campo da literatura para crianças, adolescentes e jovens são vastas, e o capricho estético na produção das ilustrações chama a atenção. Além disso, tratam de assuntos antes considerados tabus, como o dos elementos constituidores das religiões de matrizes africanas. A divulgação das fotografias sobre a África antes e depois do período pré-

\footnotetext{
${ }^{8}$ Vista a minha pele, lançado em 2003 no Brasil, sob a direção de Joel Zito; Amistad, lançado em 1997, nos Estados Unidos, sob a direção de Steven Speilberg; e Macunaíma: um herói de nossa gente, lançado em 1969, no Brasil, sob a direção de Joaquim de Andrade, foram os três filmes utilizados no decorrer do curso.

\begin{tabular}{l|l|l|l|l|l|l} 
(C) ETD - Educ. temat. digit. & Campinas, SP & v.15 & n.1 & p. 145-160 & jan./abr. 2013 & ISSN 1676-2592 \\
\hline
\end{tabular}
}


colonial, os catálogos dos museus étnicos, as fotos dos quilombos, produzidos por Fundações e ONGs, e o trabalho de vários artistas negros começam aos poucos circular nos espaços escolares. No entanto, essas produções ainda são restritas e não chegam para todos (as) os(as) professores(as).

As políticas públicas voltadas para a produção e a divulgação, assim como a distribuição, desses materiais ainda são poucas, considerando a necessidade social do trabalho sobre essa temática. Diante dessa realidade, entendemos que é urgente viabilizar possibilidades de ensino que abordem a cultura africana, com base em uma análise histórica dos elementos da cultura e da história afrodescendente e africana.

\subsection{Os filmes e a história e a cultura afro-brasileira e africana em sala de aula: é possível esse diálogo?}

As respostas referentes ao uso dos filmes e aquelas relativas à Lei 10.639/2003 nos levam a pensar em como fazer. Como o (a) professor (a) deve proceder na sala de aula? Quais são as relações que o (a) professor(a) estabelece com os(as) alunos(as) e o conteúdo? Afinal, como ensinar história e cultura africana e afro-brasileira na Educação Básica?

Uma proposta possível, mas não única, é adotar uma metodologia de ensino que utilize filmes como fonte de pesquisa histórica na ação pedagógica. A narrativa fílmica oferece a oportunidade de conhecer uma outra lógica de produção da história, que questione o modo linear de transmissão de conteúdos, preestabelecido pelos padrões eurocêntricos, ainda predominantes em nossa realidade educacional. Nesse sentido, é imprescindível contar com outras possibilidades de abordagem do próprio conhecimento científico, isto é, conhecer outras formas de saber, outras formas de ser e de existir enquanto sujeitos históricos, sociais e culturais.

Nesse momento da pesquisa, utilizamos a recomendação de Costa (2008) de não falar pelos "outros" e, sim, deixar que esses "outros" tenham a possibilidade de expressar suas realidades sociais. Por isso, perguntamos aos (as) professores (as): Há possibilidade de trabalhar filmes na sala de aula para abordar aspectos da cultura africana e do negro no Brasil? ( ) Sim. Quais? ( ) Não.

As respostas dos (as) professores (as) confirmam que essa relação é possível. Porém, no momento de estabelecer a relação entre os filmes e a cultura afro-brasileira e \begin{tabular}{l|l|l|l|l|l|l|} 
(C) ETD -Educ. temat. digit. & Campinas, SP & v.15 & n.1 & p. 145-160 & jan./abr. 2013 & ISSN 1676-2592 \\
\hline
\end{tabular} 
africana, obtivemos as mais diversas respostas, que permitiram definir algumas categorias de acordo com a nossa subjetividade.

\subsection{Categoria A: relação por meio dos conteúdos (36\%)}

Esta categoria abrange as respostas dos (as) professores(as) que, ao se posicionarem afirmativamente à questão, priorizaram um conteúdo e/ou um tema como forma de estabelecer um diálogo entre os filmes e a história e cultura afro-brasileira: "Sim, dança, música, comidas, vestimentas, costumes, organização social, racismo, forma de trabalho entre outras" (P17(f), grifo nosso). A resposta da professora indica a viabilidade de vincular o filme com o tema preestabelecido.

\subsection{Categoria B: relação por meio dos filmes (32\%)}

Esta categoria abrange os (as) professores (as) que responderam afirmativamente ao questionamento e, ao estabelecer uma vinculação entre os filmes e a cultura afrobrasileira e africana, citaram filmes, sem estabelecer quais conteúdos ou temas trabalhariam com essas películas: "Sim, Quilombo dos Palmares, Xica da Silva" (P2(m), grifo nosso). Esta resposta sugere que o professor usa a subjetividade do (a) aluno (a), ao assistir ao filme, para abordar os conteúdos, permitindo que o(a) aluno(a) possa visualizar algo além do que o(a) professor(a) imaginava trabalhar com aquela obra fílmica. No entanto, o(a) docente que não estabelece um objetivo para o filme projetado pode levar os(as) alunos(as) a ver a narrativa somente como entretenimento, perdendo ela sua dimensão pedagógica em sala de aula.

\subsection{Categoria C: não estabeleceu a relação (32\%)}

Os sujeitos desta categoria, apesar de responderem afirmativamente à questão, não fizeram a relação filme-conteúdo. Há respostas que pedem sugestões para trabalhar filmes em sua ação pedagógica. Por exemplo: "Sim, preciso de sugestões" (P18(f), grifo nosso). Essa professora sugere que, embora reconheça o potencial pedagógico dos filmes para abordar aspectos da cultura afro-brasileira e do negro do Brasil, ainda não 
conseguiu visualizar como fazer. O fato de pedir sugestões indica que ela está disposta a utilizar a obra fílmica como fonte em sua ação pedagógica.

Independentemente da categoria, todos (as) os (as) professores (as) responderam que é possível utilizar filmes como fonte de pesquisa histórica no ensino da história e da cultura africana e afro-brasileira. Isso demonstra que os sujeitos pesquisados reconhecem o potencial pedagógico da filmografia, mesmo que ainda não saibam explorar as narrativas fílmicas de maneira a ajudar seus(suas) alunos(as) a visualizar o novo, o "outro".

Ao entendermos os filmes como artefato cultural, como faz Hall (1997), compreendemos que uma produção filmográfica é produzida em um universo cultural repleto de ideologias formadoras de opinião. O cinema, como meio propagador de idéias políticas, econômicas e sociais, pode ser um veículo eficaz no processo de massificação e consolidação de ideologias que se sustentam em uma lógica da aparência. Turner (1997) argumenta que as ideias e as representações sociais veiculadas no cinema tendem a esconder dos homens a maneira como suas relações sociais foram produzidas e a origem das formas sociais de exploração econômica e de dominação política. É justamente esse ocultamento da realidade social que podemos chamar de Ideologia. O poder político e econômico de um grupo social legitima as condições sociais de exploração e de dominação, de tal forma que parecem verdadeiras e justas.

Ao utilizar o filme como fonte de estudo ou como ferramenta pedagógica que visa a construir uma sociedade multirracial com base na diversidade cultural, é preciso trabalhar em uma perspectiva crítica. Ou seja, perceber que o registro das ações humanas representadas na tela precisa ser decodificado, interpretado e, muitas vezes, desconstruído, porque os filmes trazem em suas narrativas um discurso, uma representação do real que geralmente estão eivados de ideologias e pontos de vista sobre a narrativa social.

Para Leite (2003), é necessário que o uso de filmes na educação escolar seja tratado como um elo para repensar a relação professor(a)-conteúdo-aluno(a). Não caberá mais ao(à) aluno(a) assimilar o conteúdo do discurso dominante, mas, com a mediação do(a) professor(a), constituir a sua própria visão sobre a sociedade, para que docentes e discentes desenvolvam as ferramentas necessárias para desconstrução e 
reconstrução da linguagem fílmica, a fim de possibilitar a elaboração democrática do saber sistematizado.

\section{OS FILMES COMO POSSIBILIDADES DE REFLEX̃̃es SOBRE O ENSINO DA HISTÓRIA E CULTURA AFRO-BRASILEIRA E AFRICANA}

Observamos, no decorrer do curso, que muitos foram os dilemas e as inquietações provocadas pela Lei 10.639/2003 nos/nas professores (as) desta pesquisa. Mas, ao mesmo tempo, a Lei proporcionou a eles repensar as suas práticas pedagógicas e perceber como elas estão relacionadas com os processos sociais.

No curso de extensão "O cinema no ensino de história e cultura afro-brasileira e africana na educação básica", enfatizamos sempre a importância de praticar um constante questionamento de nossas ações pedagógicas e dos conhecimentos escolares. Os dados indicam que o objetivo do curso foi alcançado, porque possibilitou aos participantes perceberem os filmes como fonte de pesquisa para o ensino da história e da cultura afro-brasileira e africana na educação básica. Por exemplo, na fala de alguns(algumas) professores(as) fica evidente a reflexão sobre a questão racial utilizando a filmografia:

\footnotetext{
O curso ofereceu várias formas de abordar diversidade racial; esclarecer algumas dúvidas sobre como utilizar o cinema como recurso didático. Consegui propiciar novas formas de ver e pensar a questão racial, neste sentido foi ótimo, pois era isso que eu esperava. Como também a forma de conduzir a discussão em grupo, trazendo novos elementos para o "velho sempre" senso comum (P16 (f), grifo nosso).
}

A fala de P16 (f) confirma que a discussão realizada durante o curso, utilizando os filmes como fonte de pesquisa histórica, propiciou a ela novas formas de ver e pensar a diversidade cultural. Novos olhares para a questão das relações raciais no Brasil são um passo importante para a construção de uma educação escolar que proporcione às novas gerações uma nova interpretação da história e uma nova abordagem na construção dos conhecimentos, dando visibilidade aos mais diferentes grupos sociais.

Os dados dos tópicos anteriores e as falas dos (as) professores(as) demonstram sensibilização para temas que não são costumeiramente discutidos no espaço escolar, como a diferença e a igualdade em sala de aula. 
O curso foi muito importante para minha prática pedagógica, principalmente pela oportunidade de ver e ouvir relatos que demonstram a preocupação do nosso grupo de professores em evidenciar o que é a DIFERENÇA que nos completa, e é o que de mais rico tem em nossa sociedade. Acredito que ainda há muito que avançar, principalmente entre professores para que as falas preconceituosas presentes cotidianamente no espaço escolar com o sentido de naturalização dessas idéias de melhor ou pior de acordo com a cor, sendo que as condições sociais fazem uma grande diferença no desempenho, na compreensão de mundo, na valorização do conhecimento $e$ do outro enquanto IGUAL, em que se pese o conceito de Igual e sua significação para os alunos. Sendo assim, colocar em pauta de discussão a sociedade brasileira e sua formação deve ser uma questão presente em sala de aula e não somente relacionados com assuntos específicos da disciplina de História (P19(f), grifo nosso).

A tensão entre igualdade e diferença está se constituindo como um debate profícuo na educação ultimamente. O diálogo no campo teórico que pudemos realizar aqui e nos ofereceu e oferece uma chave de interpretação dessas tensões está pautado nas formulações de Candau (2006) e de Santos (2006). Candau destaca que a tensão entre igualdade e diferença é uma questão fundamental no momento atual. Para alguns, a construção da democracia tem que colocar a ênfase nas questões relativas à igualdade e, portanto, eliminar ou relativizar as diferenças. Existem também posicionamentos que enfatizam a diferença, ficando a igualdade em segundo plano (CANDAU, 2006).

Com o advento das questões culturais e da forte presença de movimentos sociais que reivindicam suas especificidades, não dá mais para pensar as práticas pedagógicas baseadas somente em questões econômicas, porque passamos a presenciar debates entre a luta pela igualdade ou pela afirmação de uma diferença nos espaços escolares.

O problema não é afirmar um pólo e negar o outro, mas sim termos uma visão dialética da relação entre igualdade e diferença. Hoje em dia não se pode falar em igualdade sem incluir a questão da diversidade, nem se pode abordar a questão da diferença dissociada da afirmação da igualdade. (CANDAU, 2006, p. 82)

A fala de P19 (f), ao responder quais as contribuições que o curso ofereceu a ela, leva-nos a perceber que, por meio das narrativas fílmicas, ela visualizou que a diferença e a igualdade não são conceitos opostos e, hoje em dia, igualdade e diferença se complementam.

Quando voltamos a esta discussão, com vista à efetivação da Lei 10.639/2003, em vários momentos no curso, foi realizada a pergunta: Devemos reconhecer as 
especificidades históricas da população afro-brasileira negra ou continuar a educar todos (as) os(as) alunos(as) como se fossem iguais, independentemente de etnia ou raça?

Com certeza, há muitas discussões sobre a possível resposta a esta pergunta, mas, apesar disso, existem professores (as) que se mobilizam para o exercício de questionamento de diversos conhecimentos que são dados como naturais e verdadeiros, como pode ser visualizado neste relato: "Novos olhares sobre a cultura africana, ou mesmo sobre as culturas. A partir do curso já trabalhei outras versões da história com os alunos, como por exemplo: choques linguísticos” (P20 (f), grifo nosso).

O curso de extensão "O cinema no ensino de história e cultura afro-brasileira e africana na educação básica" mostrou a necessidade de mobilizar os (as) professores(as) para desconstruir paradigmas e enfrentar inevitáveis conflitos na sala de aula, para articular e promover uma educação que considere as relações étnico-raciais, como propõe a Lei 10.639/2003. Os filmes, portanto, podem ser um dispositivo midiático propício para isso, desde que seja percebido como um articulador de representações culturais sobre o "eu" e "outro".

\section{CONSIDERAÇÕES}

O curso de extensão teve como finalidade oferecer aos(às) professores(as) formação para conhecer os diversos grupos sociais que compuseram a população brasileira. Entendemos que é possível construir uma educação que desnaturalize os conhecimentos que ainda marginalizam a história e a cultura afro-brasileira e africana.

No curso por nós organizado para utilizar filmes como fonte de pesquisa histórica, tendo como objetivo discutir as questões sobre a negritude, ficou evidente, nas falas e nas produções escritas dos(as) professores(as), o impacto provocado pelas narrativas fílmicas. Os conceitos como raça, etnia, igualdade, diferença, cultura, conhecimento foram problematizados. Muitas tensões, medos e contradições manifestados entre os professores participantes desta investigação possibilitaram o diálogo entre as várias subjetividades e as posturas pessoais, questionando os preconceitos historicamente assumidos.

Concluímos que a intervenção pedagógica de desconstruir as verdades socialmente impostas por meio das narrativas fílmicas é um caminho metodológico de 
uma pedagogia contra-hegemônica. Entendemos que a formação de professores, especialmente no ensino de história e cultura afro-brasileira e africana na Educação Básica, pode proporcionar um avanço na educação escolar, utilizando os recursos midiáticos com base nos estudos culturais.

\section{REFERÊNCIAS}

BRASIL. Diretrizes curriculares nacionais para a educação das relações étnicoraciais e para o ensino da História afro-brasileira e africana. Brasília/DF: SECAD/ME, 2004.

BRASIL. Lei $n^{o} 10.639$, de 9 de janeiro de 2003. Altera a Lei $n^{\circ} 9.394$, de 20 de dezembro de 1996, que estabelece as diretrizes e bases da educação nacional, para incluir no currículo oficial da rede de ensino a obrigatoriedade da temática "História e Cultura Afro-Brasileira", e dá outras providências. Diário Oficial da União, Brasília, 10 jan. 2003.

CANDAU. Maria Vera. Educação intercultural e cotidiano escolar. Rio de Janeiro: 7 Letras, 2006.

COSTA, Marisa Vorraber. Currículo e pedagogia em tempo de proliferação da diferença: In ENCONTRO NACIONAL DE DIDÁTICA E PRÁTICAS DE ENSINO, 14., 2008, Porto Alegre. Anais do... Porto Alegre: Ed. PUCRS, 2008. (Trajetórias e processos de ensinar e aprender: sujeitos, currículos e culturas).

DUARTE, Rosália. Cinema \& educação. Belo Horizonte: Autêntica. 2002.

FELIPE, Delton Aparecido. Narrativas para alteridade: o cinema na formação de professores e professoras para o ensino de história e cultural afro-brasileira e africana na educação básica. 152 f. 2009. Dissertação (Mestrado em Educação) - Universidade Estadual de Maringá, PR, 2009.

HALL, Stuart. A identidade cultural na pós-modernidade. Rio de Janeiro: DP\&A, 1997.

LEITE, Sidney Ferreira. O cinema manipula a realidade? São Paulo: Paulus, 2003.

LOURO, Guacira Lopes. O cinema como pedagogia. In: LOPES, E. M.T.; FARIA, L.M; VEIGA, C. G. 500 anos de educação no Brasil. Belo Horizonte: Autêntica, 2000.

NOMA, Amélia Kimiko. O cinema como fonte do ensino e da pesquisa em educação. In: SEMINÁRIO DE PESQUISA PPE, 2000, Maringá. Anais do... Maringá: UEM, 2000 . 
NOVA, Cristiane Carvalho da. Novas lentes para a história: uma viagem pelo universo da construção da história pelos discurso áudio-imagéticos. 1999. Dissertação (Mestrado em Educação), Setor de Ciências da Educação - Universidade Federal da Bahia. Salvador, 1999.

OLIVEIRA, Luiz Fernandes; LINS, Maria Regina. Memórias e imagens destabilizadora para a (re) educação das relações étnico-raciais. Teias, Rio de Janeiro, ano 9, n. 17, p. 70-78, jan./jun. 2008.

ROSENSTONE, Robert A. A história nos filmes, os filmes na história. Tradução de Marcello Lino. São Paulo: Paz e Terra, 2010.

SANTOS, Boaventura de Souza. A gramática do tempo: para uma nova cultura política. São Paulo: Cortez, 2006.

SANTOS, Boaventura de Souza. Para uma pedagogia do conflito. In: SILVA, Luis. Heron. Novos mapas culturais, novas perspectivas educacionais. Porto Alegre: Sulina, 1996. p. 67-78.

SILVA, Ana Célia da. Desconstruindo a discriminação do negro no livro didático. Salvador: EDUFBA, 1998.

TURNER, Graeme. Cinema como prática social. São Paulo: Summus, 1997.

WOODWARD, Kathryn. Identidade e diferença: uma introdução a teoria conceitual. In: SILVA, Tomaz Tadeu (Org.). Identidade e diferença: a perspectiva dos estudos culturais. Petrópolis: Vozes, 2000. p. 33-45.

\section{Como citar este artigo:}

TERUYA, Teresa Kazuko; FELIPE, Delton Aparecido. Filmes e negritude em sala de aula: essa relação é possível?. ETD - Educação Temática Digital, Campinas, SP, v. 15, n. 1, p.145-160, jan./fev. 2013. ISSN 1676-2592. Disponível em: <http://www.fae. unicamp.br/revista/index.php/etd/article/view/2907>. Acesso em: 19 abr. 2013. 